\title{
Time to Turn Up the Volume
}

\author{
Nadia van der Linde
}

Suggested citation: $\mathrm{N}$ van der Linde, 'Time to Turn Up the Volume', AntiTrafficking Review, issue 12, 2019, pp. 194-199, www.antitraffickingreview.org

I remember my first self-organised donor panel well. It was at the Global Social Change Philanthropy Conference in Washington, DC in 2013. I had just started work as the first coordinator of the Red Umbrella Fund-the newly established fund for and by sex workers. I organised a session that would clarify the distinction between sex work and human trafficking and emphasise the need to fund sex worker organising. We had a strong panel: an awesome sex worker activist, a knowledgeable academic, a passionate service provider, and a committed funder. I was, however, in for a rude awakening: even though the line-up was great, the audience was scarce. I thought to myself, if we can't even get funders to show up and learn about sex workers' rights, how will we ever meet the needs of sex worker organisations fighting for their basic human rights?

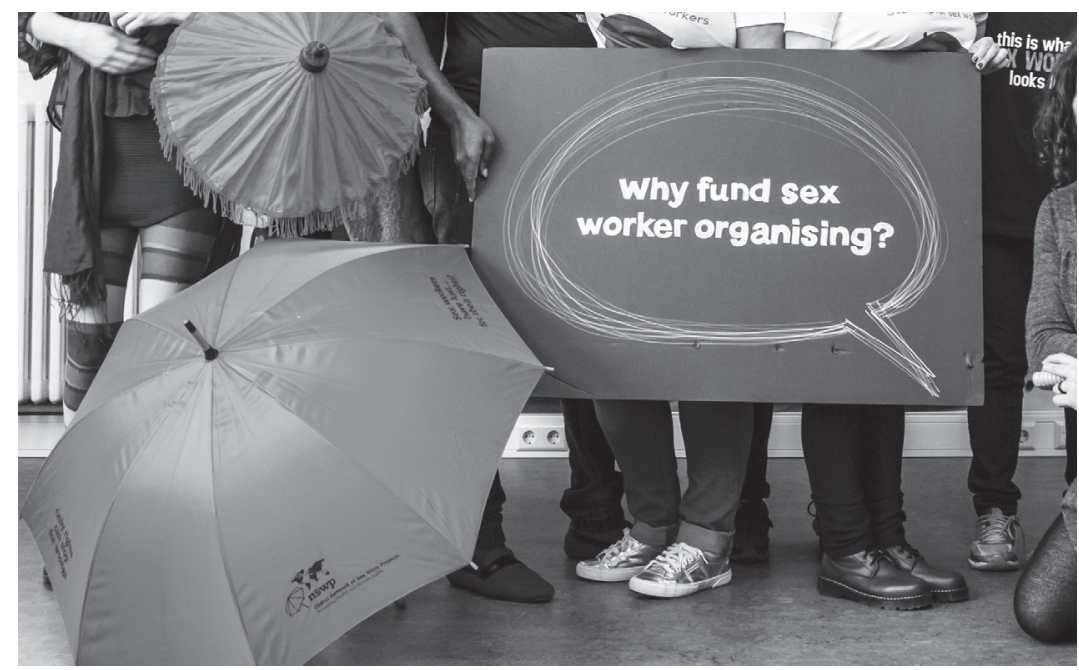

Image 1: Meeting of the Programme Advisory Committee of the Red Umbrella Fund, Amsterdam, 2017. Image credit: Vera Rodriguez, Red Umbrella Fund. 


\section{Why the Need for Donor Support?}

Sex workers are criminalised for their means of making a living in all but a handful of countries and jurisdictions. Addressing stigma and violence are key priorities of sex worker groups everywhere. For most sex workers, police are not there to protect them but perpetrate most of the violence against them. ${ }^{1}$ Harassment, confiscation of condoms, extortion, arbitrary arrest, and rape are common examples of police violence. Even in the Netherlands, where sex work is regulated, most sex workers do not report cases of physical or sexual violence to the police. ${ }^{2}$ A rare exception is New Zealand, where sex work is decriminalised and the government helps fund a sex worker organisation to provide information, services, and support to their peers. The New Zealand Prostitutes Collective and police work together to prevent violence and encourage sex workers to file a report when they experience sexual assault and other violent crimes. ${ }^{3}$

Sex workers across the world are organising against criminalisation, which puts not just their livelihood at risk but their entire lives - and those of their loved ones. They are generally recognised as marginalised and highly vulnerable in today's societies, embodying multiple layers of stigma because of the work they do, and also because they are often poor, lack formal education, belong to Indigenous or migrant populations, identify as trans or gay, or are single mothers. However, funding to support sex worker organisations and their community mobilisation efforts is scarce. ${ }^{4}$ In 2013 , foundations invested a meagre USD 11 million in grants to support sex worker rights worldwide. ${ }^{5}$

1 M Bhattacharjya, E Fulu and L Murthy, The Right(s) Evidence: Sex work, violence and HIV in Asia. A multi-country qualitative study, UNFPA, UNDP and APNSW (CASAM), Bangkok, 2015, retrieved 19 December 2018, http://www.asiapacific.undp.org/content/dam/rbap/docs/Research\%20\&\%20Publications / hiv_aids/rbap-hhd-2015-the-rights-evidence-sex-work-violence-and-hiv-inasia.pdf.

2 M Kloek and M Dijkstra, Sex Work, Stigma and Violence in the Netherlands, Aidsfonds, Amsterdam, 2018, https://www.soaaids.nl/sites/default/files/ documenten/Prostitutie/Sex\%20Work\%20Stigma\%20and $\% 20$ Violence $\% 20$ in $\% 20$ the $\% 20$ Netherlands $\% 20$ Report $\% 28$ digital $\% 29$.pdf.

3 E McKay, 'World-first partnership between NZ Police and Prostitutes' Collective', NZ Herald, 17 December 2018, https://www.nzherald.co.nz/nz/news/ article.cfm?c_id=1\&objectid=12178217.

4 J Dorf, Sex Worker Health and Rights: Where is the funding?, Open Society Institute, New York, 2006, https://www.opensocietyfoundations.org/sites/default/files/ where.pdf.

5 Mama Cash, Red Umbrella Fund and Open Society Foundations, Funding for Sex Worker Rights. Opportunities for foundations to fund more and better, Mama Cash/RUF, Amsterdam, 2014, https://www.redumbrellafund.org/report. 
Most sex worker organisations have no funding at all, but those that do receive an institutional grant usually still have annual budgets below USD 70,000 and their reliance on volunteer work remains high. At the same time, raid and rescue programmes and rehabilitation centres continue to be generously funded as, supposedly, models of supporting or 'helping' women in the sex industry.

Sex worker organisations call on funders to provide more funding that is long term and covers rent, salaries, trainings, legal services, and advocacy. They also want funders to speak up in support of sex workers' rights. ${ }^{6}$ A conversation I had recently with another human rights funder revealed that, while they had given some grants to sex worker groups before, they had never realised that most peer human rights funders still do not fund such work. We clearly need to more effectively leverage our access and knowledge to educate and activate our philanthropic peers.

\section{Changing Perspective}

The best way to educate funders is through people's lived experiences. We interviewed staff of funding organisations who had changed their perspective from assuming all sex work (or prostitution) is exploitation and trafficking to recognising sex workers as human beings who are entitled to rights, including in relation to their work. This revealed that academic evidence, UN documents, and human rights organisations' public support for sex workers' rights are all helpful, but the main lever to a more nuanced understanding comes from direct interactions with sex workers. ${ }^{7}$ We need to bring funders and sex workers in the same room.

The international donor-activist dialogue on sex work and trafficking that took place in 2008 was one notable success of getting funders to listen to sex workers. ${ }^{8}$ Members of the Global Network of Sex Work Projects (NSWP) played a crucial role in subsequent donor education, speaking from lived

\footnotetext{
Ibid.

$\mathrm{N}$ van der Linde and S Bos, 'Mind the Gap-What we learned about how funders can be moved in the right direction', Alliance Magazine, 7 September 2016, https://www.alliancemagazine.org/blog/mind-the-gap-what-we-learnedabout-how-funders-can-be-moved-in-the-right-direction.

8 CREA, NSWP and SHARP, Sex Work and Trafficking A Donor/Activist Dialogue on Rights and Funding, CREA, NSWP and SHARP, 2008, https:// www.redumbrellafund.org/wp-content/uploads/2014/07/Donor_Dialogue_ Final_REPORT_December2008.pdf.
} 
experience about the harms of many anti-trafficking initiatives on sex workers. By the end of the event, funders were united in their acknowledgement that sex workers need funding to effectively organise and stand up for their rights. Four years later, the Red Umbrella Fund was launched. ${ }^{9}$

So far, the Red Umbrella Fund has awarded 158 grants to 103 sex worker-led groups in over fifty countries. These investments have resulted in stronger organisations and leadership and increased solidarity and connections within the movement and with other movements. This is not, however, nearly enough to foster real change. For every grant awarded, applications by many other groups had to be declined due to the limited money available.

\section{Self-organising for Labour Rights}

Since the fund was established in 2012, our grantee partners have taught us how the conflation of sex work and trafficking plays out in their daily lives. It is not just that anti-trafficking policies often harm them; stigma and criminalisation also create a social climate where sex workers are at greater risk of being trafficked and survivors of trafficking may have few other options to make a living than sex work. Although they hardly ever mention it in their own publications, many sex worker groups provide crucial services and support to people who have experienced trafficking. ${ }^{10}$ Similarly, labour unions and women's organisations that stand up for domestic workers or agricultural labourers who work in poor conditions do not force them to quit their work or support incarcerating them, but instead focus on improving their labour conditions and self-organising capacity. As one sex worker at a donor-activist meeting organised by the Global Alliance Against Traffic in Women (GAATW) in Bangkok in February 2018 stated:

We are fighting for our rights, for our labour rights, for better working conditions. Sex workers and clients, for the most part, are against trafficking and exploitation. Sex workers support trafficked people, and we protect them from the police.

9 Red Umbrella Fund, The Creation of a Collaborative Fund for and by Sex Workers, 2017, https://www.redumbrellafund.org/wp-content/uploads/2014/07/RedUmbrella-Fund-The-creation-of-a-Collaborative-Fund.pdf.

${ }^{10}$ See, for example, Global Alliance Against Traffic in Women, Sex Workers Organising for Change: Self-representation, community mobilization, and working conditions, GAATW, Bangkok, 2018. 
It is no surprise that a review of the grant applications we received over the years shows that, although local contexts differ greatly, ending stigma, violence, and criminalisation are the key priorities for sex worker organisations everywhere. Sex worker organisations prevent exploitation and trafficking by providing safe spaces, information, support, and accompaniment to relevant services. ${ }^{11}$ Their campaigns for decriminalisation of sex work are crucial to build safer work environments where problems can be reported to police and justice can be sought. And where, as is highlighted by the New Zealand Prostitutes Collective, sex workers have the right to say yes, but also the right to say no. ${ }^{12}$

\section{Conclusion}

A peer activist funder recently explained the evolution of their donor advocacy strategy to me, which had gone from 'philanthro-shaming' (highlighting the urgent need to increase funding in a particular area to avoid or address a certain problem) to unapologetically using the popular concept of FOMO, the fear of missing out. Too often, he shared, we highlight funding gaps and needs, hoping it will persuade funders to fill the abyss. That may help some allied funders to expand their grantmaking, but it will not convince the sex worker rights funding 'virgins'. The reality is that even many self-identified social justice funders still claim 'neutrality' on the topic of sex workers' rights, or simply lack the courage to speak out. Those funders need to realise that they are not the first sheep to leap over the ditch. In the case of this peer activist funder, their new donor advocacy strategy, therefore, intends to take a 'jump on the bandwagon or miss out' approach, highlighting that funding sex worker organising is the thing to do, and now!

I don't think this bandwagon approach alone will do the trick, but at least we have started forming a band and developing some common tunes. Different funders have started coming together in a new collaborative effort to ensure that more funding is directed to the sex worker rights movements. Now it's time to turn up that volume and reach the right audience.

${ }^{11}$ Ibid.; see also: W Volbehr, 'Improving Anti-Trafficking Strategies: Why sex workers should be involved', Open Democracy, 17 July 2017, https:// www.opendemocracy.net/beyondslavery/wendelijn-vollbehr/improving-antitrafficking-strategies-why-sex-workers-should-be-inv.

12 NZPC, Our Right to Say Yes, Our Right to Say No, n.d., http://www.nzpc.org.nz/ pdfs/Right-to-Say-Yes-or-No-Poster.pdf. 
Nadia van der Linde is the Coordinator of the Red Umbrella Fund. She holds a Master's degree in Social Geography from the University of Amsterdam and has years of international experience, particularly in the field of sexual and reproductive rights, advocacy, and (youth) participation processes. Nadia has worked for the Youth Coalition, the Women's Global Network for Reproductive Rights, the People's Health Movement, Stichting Alexander, the Asia Pacific Network of Sex Workers and the United Nations Population Fund (UNFPA). She is the chairperson of the Prostitution Information Center in Amsterdam, the Netherlands. Email: nadia@redumbrellafund.org. 